\title{
Use of Forestry Wastes for Biosorption of Dyes and Cr (VI)
}

\author{
Nariye Berraksu, Ebru Mavioglu Ayan, and Jale Yanik \\ Department of Chemistry, Faculty of Science, Ege University, Bornova, 35100 Izmir, Turkey \\ Correspondence should be addressed to Jale Yanik; jale.yanik@ege.edu.tr
}

Received 4 June 2012; Revised 3 September 2012; Accepted 25 September 2012

Academic Editor: Shayessteh Dadfarnia

Copyright () 2013 Nariye Berraksu et al. This is an open access article distributed under the Creative Commons Attribution License, which permits unrestricted use, distribution, and reproduction in any medium, provided the original work is properly cited.

\begin{abstract}
The pine cone and oak cups pulp were used as low-cost adsorbents for the removal of basic (Basic Red 18) and acidic (Acid Red 111) dyes and $\mathrm{Cr}$ (VI) from aqueous solutions. The adsorbents were modified by $\mathrm{HNO}_{3}$ to improve their biosorption capacity. The adsorbents were characterized using scanning electron microscopy and FTIR spectroscopy. The zeta potential was determined as a function of the $\mathrm{pH}$, in order to explain the effect of $\mathrm{pH}$ on electrostatic adsorption ability of biosorbent. Modification of adsorbents with nitric acid led to an increase in accessibility of some functional groups on the surface or a decrease in negativity of surface charge. The modification of pine cone increased its adsorption capacity for the basic dye, whereas the modification of oak cups pulp decreased the adsorption ability for basic dye to some extent. The adsorption isotherms fitted the Langmuir model. The adsorption capacities were found to be $142.85,158.73$, and $156.20 \mathrm{mg} \mathrm{g}-1$ for modified and raw pine cone and oak cups pulp, respectively. The acidic dye and $\mathrm{Cr}(\mathrm{VI})$ adsorptions were much lower compared to basic dye on all tested adsorbents. The results indicated that the forest wastes (pine cone and oak cups pulp) were an attractive candidate for basic dyes from aqueous solution.
\end{abstract}

\section{Introduction}

The biosorption of organic and inorganic toxic contaminants from waste water has greatly increased because an inexpensive and more easily available adsorbent would make the removal of pollutants an economically viable alternative $[1,2]$. Numerous studies on adsorption properties of forestry and agricultural wastes, as naturally occurring and low-cost adsorbents, have been documented. A number of lignocellulosic wastes have been tried for dye and metal removal. These include wood sawdust [3, 4], orange peel $[5,6]$, tobacco dust [7], tea waste [8], hen feathers [9], sunflower seed hull [10], palm kernel fibre [11], coir pith [12], peanut hull [13], grape stalks [14], soya cake [15], soy meal hull [16], sugar beet pulp [17], and Canola hull [18]. In addition, a number of studies exist on the modification of the agricultural wastes to increase their adsorption capacity. Gupta and Rastogi. have reported excellent biosorption capacity of acid-treated algal biomass for the removal of lead, cadmium and hexavalent chromium [19]. The chemically treated P. oceanica fibres with nitric acid and phosphoric acid had showed enhancement in the reactive dye removal due to the protonation of the biomass surface for acidic attacks [20]. Similarly, treatment of narrow-leaved cattail with formaldehyde + sulfuric acid increased the sorption ability for direct and reactive dyes due to the increase of positively charged molecules on the surface of adsorbent [21]. The modification of wood shavings with $\mathrm{Na}_{2} \mathrm{CO}_{3}$ and $\mathrm{Na}_{2} \mathrm{HPO}_{4}$ increased the adsorption ability for the basic dye (Methylene Blue), whereas the modification of with $\mathrm{HCl}$ decreased the sorption ability for Methylene Blue to some extent [22]. In addition, the biosorbent having high cationic sorption capacity was obtained by thermochemically modification of biomass with citric acid [23].

In this study, forestry wastes (pine cone and oak cups pulp) were used for dyes and $\mathrm{Cr}$ (VI) removal and acid pretreatment of biomass was adopted to improve their removal, efficiency. The Anatolian vegetation is very rich on account of species of trees. The oak trees are widely found and distributed on the Aegean region of Anatolia. The acorn cups of Turkish oak (Quercus alegilops) containing high percentage of hydrolysable (pyrogallol) group of tannin are internationally called as "Valonea." The matured acorn cups are picked between October and March, dried and sent to the extract factory. The Valonea is treated with hot water in order to leach the tannin. The vegetable extract obtained from Valonea is named as "Valex" and used in leather manufacture 
as tanner while the residue from extraction (oak cups pulp) is disposed by incineration. On the other hand, Pinus pinea L. is an economically important tree in the Mediterranean area, mainly in Spain, Portugal, Italy, Greece, Albania, and Turkey and has a significant role in soil conservation, landscape architecture, and for its edible seeds. Its plantation has been highly promoted by European policy of the forestation of croplands. Turkey has 35000 ha of stone pine forest, and pine cones are widely used as a domestic fuel in forest villages or are retained in forest.

The aim of this study is to investigate the potential of cone of stone pine (Pinus pinea L) and oak cups pulp waste acorn as alternative low-cost adsorbent for basic and acidic dyes and Cr (VI) metal ion. Although biosorption using various lowcost biomass materials has been widely studied, there has not been any report on oak cups pulp and pine cone.

\section{Materials and Methods}

2.1. Preparation of Adsorbent. The oak cups pulp valex residue was supplied by Valex plant in Salihli/Izmir, the cones of Pinus pinea L. was supplied from a forest in the Izmir area. Both two biomass samples were air dried and ground and sieved to particle size $0.20-0.5 \mathrm{~mm}$. Some properties and composition of biosorbents are given in Table 1.

Both the oak cups pulp (OC) and pine cone (PC) samples were washed with distilled water to remove the surface-adhered particles and water soluble materials and was dried at $110^{\circ} \mathrm{C}$ overnight. Modified oak cups pulp (OC$\mathrm{N}$ ) and pine cone (PC-N) were prepared by suspending the sorbent material in $1 \mathrm{M} \mathrm{HNO}_{3}$ solution for 24 hours at room temperature rinsing with deionized water and drying at $110^{\circ} \mathrm{C}$ overnight [20].

Basic and acidic dyes used in this study were Basic Red 18 and Acid Red 111. All the dyes (Bayer) were used as received. Their chemical structures are given in Figure 1. Hexavalent chromium solutions were prepared by dissolving appropriate amounts of potassium dichromate $\left(\mathrm{K}_{2} \mathrm{Cr}_{2} \mathrm{O}_{7}\right.$, Merck).

2.2. Adsorbent Characterization. The electrophoresis method was used to determine the zeta potential of the adsorbents, by using Zeta-Meter 3.0+ equipped with a microprocessor unit [24]. In order to obtain suspended particles in the

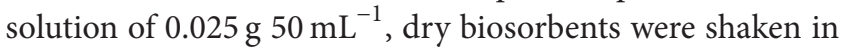
bidistilled water for 24 hours at room temperature. Then, the zeta potential of the particles was measured as a function of $\mathrm{pH}$ between 2 and 10 without addition of electrolytes in bidistilled water $(<2.0 \mu \mathrm{S} / \mathrm{cm})$. The $\mathrm{pH}$ of dispersions was adjusted by adding either $\mathrm{HCl}$ or $\mathrm{NaOH}$ solutions.

Attenuated total reflectance infrared (ATR/IR) spectra of the biosorbents were taken by using a spectrophotometer (Spectrum 100, Perkin-Elmer). The scanning electron microscope (SEM) analyses were done by JSM-6060 JEOL instrument.

2.3. Batch Sorption Experiments. Batch experiments were carried out in $250 \mathrm{~mL}$ of Erlenmeyer by shaking a fixed mass of dry samples with $100 \mathrm{~mL}$ of adsorbate solution for the desired concentration, $\mathrm{pH}$, and contact times. The $\mathrm{pH}$ was adjusted, adding either $\mathrm{HCl}$ or $\mathrm{NaOH}$. The filtrates were analyzed for residual acidic and basic dyes concentrations using the UV-visible spectrophotometer (UV-160A, Shimadzu) at 504 and $484 \mathrm{~nm}$, respectively. For residual Cr (VI) concentrations, the filtrates were analyzed by a reaction with 1,5-diphenylcarbazide followed by absorbance measurement at $540 \mathrm{~nm}$ using the UV-visible spectrophotometer.

In order to obtain the adsorption isotherm $100 \mathrm{~mL}$ of the test solutions of various dye (10-150 ppm) and Cr (VI) (10-20 ppm), concentrations were added to predetermined amount of adsorbent in Erlenmeyer, and the suspensions were shaken at $150 \mathrm{pm}$ for an experimentally predetermined time to establish the equilibrium, after adjustment of $\mathrm{pH}$. In all sets of experiments, each test was carried out in duplicate and the average results are presented. The results were reproducible, and the standard deviations were found to be $\pm 2.4 \%$.

\section{Results and Discussion}

3.1. Characterization of the Adsorbents. Fourier transform infrared spectral analysis of natural and modified biosorbents displayed a number of absorption peaks corresponding to different functional groups indicating their complex structures. The spectrum of all tested adsorbents are given in Figure 2 and band assignments of typical IR spectrum are summarized in Table 2. It has been seen that all include common bands with some differences from the comparison of all the spectra.

It is worth noting that the spectra of modified sorbents did not differ significantly from the spectrum of unmodified sorbents. Similar result was obtained by Janoš et al. who compared the sorption capability of the modified wood with that of the unmodified wood for dyes [22].

The most significant difference in adsorbents is that the $\mathrm{C}=\mathrm{O}$ stretching band in $\mathrm{PC}-\mathrm{N}$, it appears at $1718 \mathrm{~cm}^{-1}$ (corresponding to stretching in carboxylic acid). The displacement to lower wave numbers may be attributed to hydrolysis of esters in natural pine corn during modification with $\mathrm{HNO}_{3}$ [25]. According to the FT-IR results, we can conclude that pine cone and oak cups pulp maintained its functional groups in the bulk after modification with $\mathrm{HNO}_{3}$.

The polar functional groups, such as alcohols, carboxylic acids, and phenolic hydroxides in lignocellulosic materials groups may contribute to the occurrence of charged sites on the surfaces of biomass [7]. The surface charge of the biomaterial plays an important role in electrostatic adsorption on the biosorbent. The surface charge of adsorbents was investigated measuring zeta potential (ZP). $\mathrm{ZP}$ is variable with the surface potential and the thickness of electric double layer. The degree of repulsion between charged particles in dispersion is indicated by the zeta potential.

Figure 3 shows the variation of zeta potential as a function of $\mathrm{pH}$. As seen from Figure 3, the surface of all biosorbents was negative, and the negativity increased as the $\mathrm{pH}$ of the solution increased slightly from 2.0 to 10 . This suggests that deprotonation or/and ionization of acidic functional groups of the lignocellulosic material increased by increasing the $\mathrm{pH}$ of solution. 


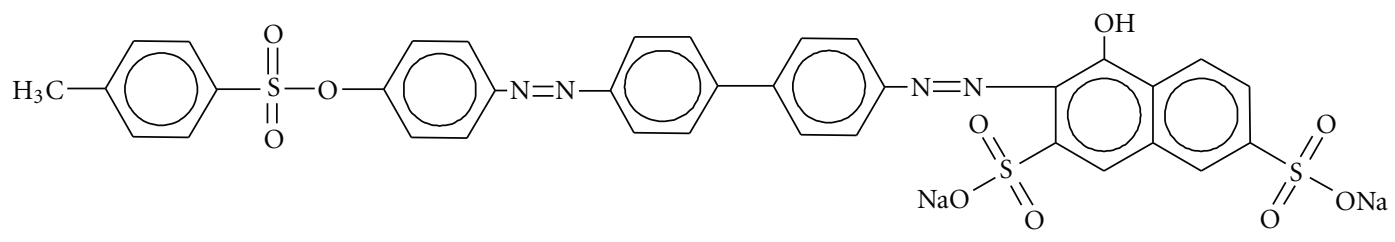

Acid Red 111

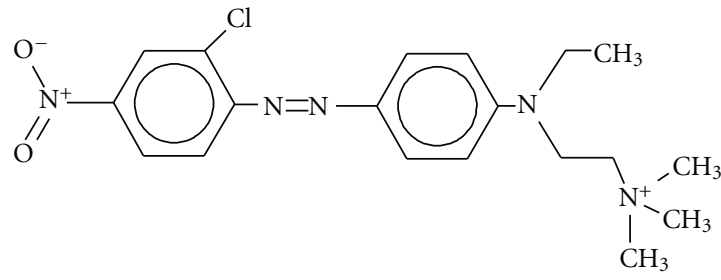

Basic Red 18

FIGURE 1: Chemical structure of investigated dyes.

TABle 1: Properties of biosorbents.

\begin{tabular}{lccccc}
\hline & Ash (wt\%) & Lignin (wt\%) & Cellulose (wt\%) & Hemicellulose (wt\%) & Extractives (wt\%) \\
\hline Pine cone & 0.9 & 31.4 & 47.2 & 15.7 & 4.8 \\
Oak cups pulp & 7.2 & 34.3 & 12.3 & 43.6 & \\
PC-N & 0.18 & & & & \\
OC-N & 1.09 & & & & \\
\hline
\end{tabular}

The negative charge values should be favorable to the attraction between active sites in adsorbent and positive charges of adsorbate, resulting in an electrostatic interaction. Although FTIR spectra suggested that chemical treatment procedure did not change substantially the lignocellulosic structure it, however, changed surface charge of the sorbents.

The zeta potential plots show differences between the natural and modified biosorbents. Unexpectedly, the surface charge of modified biosorbents was less negative than that of natural biosorbents. In the case of untreated material, polar functional groups due to the holocellulose and lignin are covered by noncellulose compounds. It is expected that the acid treatment removing of these compounds led to an increase in the negative zeta potential by the improved accessibility of anionic groups [26]. But in this study, we obtained opposite result. It was reported that the electrokinetic potential of fibers, depends on the chemical constitution and polarity of the fiber surface, the microstructure of the fiber and its swelling behavior in water [27]. Swelling increases the size of the active surface on adsorbent which led to an increase in the negative charge. The modification process might decrease the hydrophilic behavior of the fiber surface. Therefore, the surface charge of PC-N and OC-N is less negative than that of PC and OC.

The SEM micrographs of PC, PC-N, OC, and OC-N show typical lateral rack type of structure (Figure 4). It should be noted that all of the biosorbents exhibited only a color change, which could be observed with even naked eye, after the modification process.
3.2. Basic Dye Adsorption. The $\mathrm{pH}$ is one of the most important factors in the adsorption of dye. This is partly due to the fact that hydrogen ions themselves are strong competing adsorbates, and partly that $\mathrm{pH}$ of the solution influences surface charge of adsorbent. The influence of $\mathrm{pH}$ on the removal of Basic Red 18 was studied at different contact time over a $\mathrm{pH}$ range $6.0-10.0$ at which the color was stable.

It is well known that adsorption of basic dyes is unfavorable at acidic $\mathrm{pH}$ due to the presence of excess $\mathrm{H}^{+}$ions which compete with the dye cation for adsorption sites [8]. However, the number of the negatively charged sites on adsorbent increases as the $\mathrm{pH}$ of the system increases, favoring the adsorption of dye cation due to electrostatic attraction. Figure 5 shows the effect of $\mathrm{pH}$ and contact time on dye removal. The dye uptake on PC was increased by the increasing $\mathrm{pH}$. A similar trend was reported for the adsorption of dyes such as malachite green onto sawdust [23] and hen feathers [9], Methylene Blue and Red Basic 22 onto prehydrolysed beech sawdust [4], methyl violet onto seed hull [10], and Methylene Blue onto palm kernel fibre [11].

On the other hand, it was observed that the dye uptake increased with the contact time. As shown in Figure 5, the adsorption of Basic Red 18 was rapid within the first $6 \mathrm{~h}$ of contact time and then was gradual until equilibrium. It was established that within the eight hours, almost $93 \%$ of adsorption was achieved at $\mathrm{pH} 10$. The equilibrium time of $8 \mathrm{~h}$ and the $\mathrm{pH} 10$ were found to be sufficient for further studies. The influence of $\mathrm{pH}$ on the removal of Basic Red 18 by 


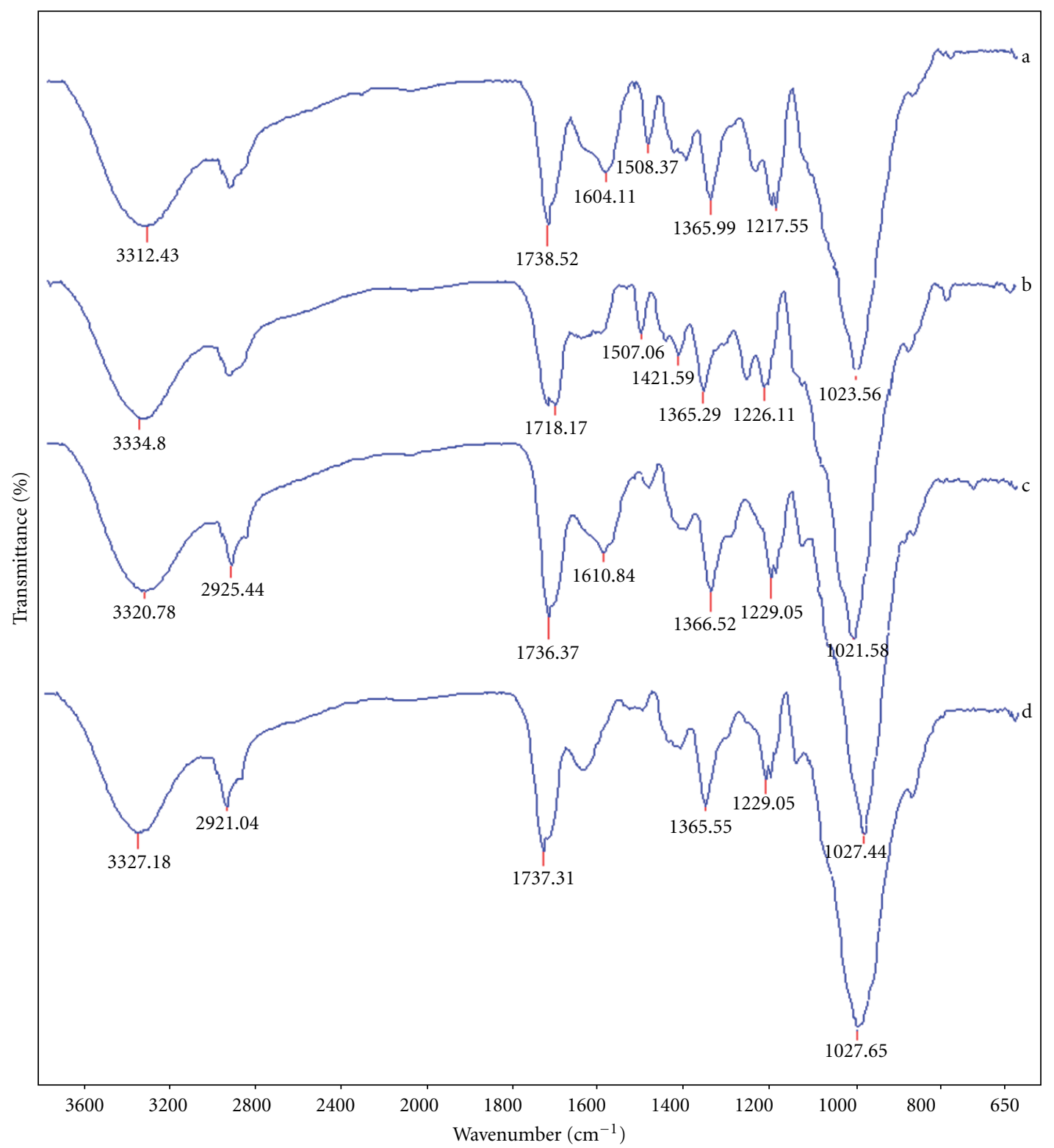

Figure 2: FT-IR spectra of PC (a), PC-N (b), OC (c), and OC-N (d).

OC was also investigated at different contact times between 2 and 24 hrs (not presented here). In contrast to PC, the dye up take on $\mathrm{OC}$ was independent of the $\mathrm{pH}$ between 6 and 10. The same trend has also been reported in the removal of basic dye by some other materials $[5,10,12,28]$. There was an approximately $10 \%$ variation in adsorption capacity for the contact times between 4 and $24 \mathrm{hrs}$. Therefore, in order to maximize the cost-effectiveness of adsorption operation, it was decided not to extend the adsorption for larger period than 4 hrs. It is worth nothing that the optimum contact time was independent of the $\mathrm{pH}$. This observation showed that an external surface mass transfer or film diffusion process may also control the sorption process as well as chemical sorption process. For the adsorption of Basic Red 18 on OC, the equilibrium time of 4 hrs and the $\mathrm{pH} 6$ were found to be sufficient for further studies.

In the case of modified pine cone (PC-N), dye uptake considerably increased above $\mathrm{pH} 8$ (Figure 6). The uptake of dye by PC-N occurred faster than PC, corresponding to 93.0\% removal at an equilibrium time of $4 \mathrm{hrs}$. It is clearly understood that the number of available adsorption sites area increased by the modification of $\mathrm{PC}$ with $\mathrm{HNO}_{3}$ treatment, although its surface is less negative than that of native pine cone. The relative increase in the removal of dye after contact time of 4 hrs for PC-N was not significants, and hence, it was fixed as the optimum contact time.

On the other hand, the dye uptake on OC-N was not considerably changed by increasing of $\mathrm{pH}$ as in the case of 
TABLE 2: The main atomic groups and structures of adsorbents.

\begin{tabular}{|c|c|c|c|c|c|}
\hline Wavenumber $\left(\mathrm{cm}^{-1}\right)$ & Infrared absorption and structures & $\mathrm{PC}$ & PC-N & $\mathrm{OC}$ & OC-N \\
\hline $1021-1023$ & C-O deformation & + & + & + & + \\
\hline $1217-1229$ & $\mathrm{C}-\mathrm{O}$ stretching (phenols) & + & + & + & + \\
\hline 1366 & $\mathrm{C}-\mathrm{H}$ bending (methyl group) & + & + & + & + \\
\hline $1736-1738$ & $\mathrm{C}=\mathrm{O}$ stretching (esters) & + & - & + & + \\
\hline 1718 & $\mathrm{C}=\mathrm{O}$ stretching (carboxylic acid) & - & + & - & - \\
\hline $2920-2925$ & $\mathrm{C}-\mathrm{H}$ stretching (aliphatic structures) & + & + & + & + \\
\hline $3312-3335$ & -OH (phenols, alcohols, and carboxylic acids) & + & + & + & + \\
\hline
\end{tabular}

TABLE 3: Parameter of the Langmuir adsorption model of dyes and $\mathrm{Cr}$ (VI) (at $25 \pm 0.2^{\circ} \mathrm{C}$ ).

\begin{tabular}{lccccccrrr}
\hline \multirow{2}{*}{ Adsorbents } & \multicolumn{3}{c}{ Basic Red 18 } & \multicolumn{3}{c}{ Acid Red 111 } & \multicolumn{3}{c}{ Cr (VI) } \\
& $S_{M} \mathrm{mg} \mathrm{g}^{-1}$ & $K_{L} \mathrm{~L} \mathrm{mg}^{-1}$ & $R^{2}$ & $S_{M} \mathrm{mg} \mathrm{g}^{-1}$ & $K_{L} \mathrm{~L} \mathrm{mg}^{-1}$ & $R^{2}$ & $S_{M} \mathrm{mg} \mathrm{g}^{-1}$ & $K_{L} \mathrm{~L} \mathrm{mg}^{-1}$ & $R^{2}$ \\
\hline PC & 142.85 & 0.26 & 0.96 & 7.54 & 0.09 & 0.97 & 7.16 & 16.24 \\
PC-N & 158.73 & 0.75 & 0.99 & 7.92 & 0.49 & 0.98 & 4.19 & 0.99 \\
OC & 156.20 & 0.32 & 0.97 & 7.99 & 0.16 & 0.98 & 6.54 & 0.98 \\
OC-N & 133.33 & 0.24 & 0.99 & 9.95 & 0.14 & 0.99 & 7.48 & 1.91 & 0.97 \\
\hline
\end{tabular}

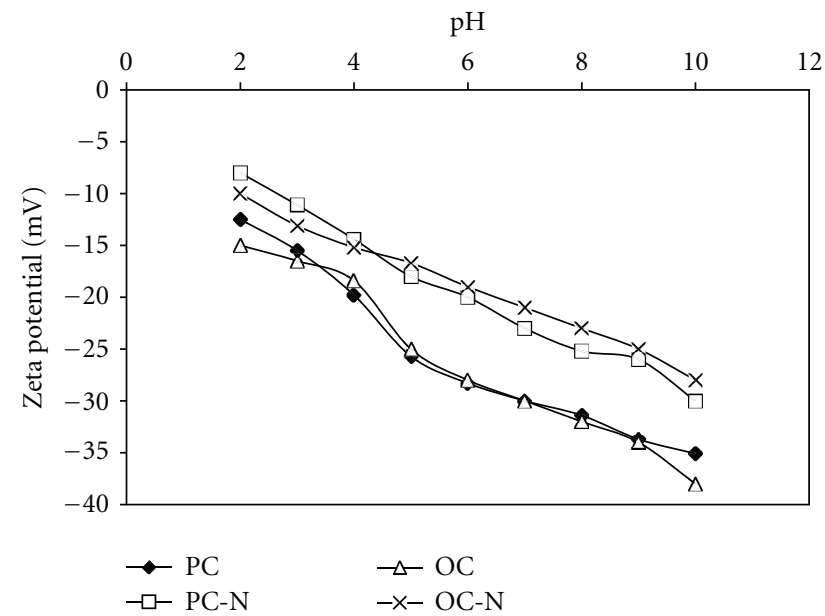

FIgURE 3: The zeta potential curves as a function of $\mathrm{pH}$ for raw and modified PC and OC.

OC. Since $100 \%$ removal was obtained for a contact time of $4 \mathrm{hrs}$ at $\mathrm{pH} 6$, the equilibrium time of $4 \mathrm{hrs}$ and the $\mathrm{pH} 6$ were found to be sufficient for isotherm studies.

3.3. Acidic Dye Adsorption. Although the basic dye sorption on woody biomass is mainly a chemisorption process, the acidic dye adsorption is more or less physical process [22]. Due to the negatively charged characteristics of cellulose materials in aqueous medium [29], the lignocellulosic adsorbents have been found to have low adsorption capacities to anionic dyes dyestuffs.

In this study, we aimed to enhance the adsorption capacity of lignocellulosic adsorbents by modification and to study their adsorption behavior toward acidic dye (a cationic dye), comparatively. There is limited study on modification of lignocellulosic materials to enhance their anionic dye adsorption capacity. It has been shown that treatment of
Posidonia oceanica (L.) leaf sheaths with $\mathrm{H}_{3} \mathrm{PO}_{4}$ and $\mathrm{HNO}_{3}$ solutions increased the adsorption efficiency up to $80 \%$ for a reactive textile dye [20]. On the other hand, the treatment of wood shavings with $\mathrm{HCl}$ increased the sorption ability for Egacid Orange (acid dye) to some extent [22]. The improving of the dye adsorption capacity through chemical treatment of the biomass was also reported by other authors $[13,21,30]$.

The effect of $\mathrm{pH}$ on the amount of Acid Red 111 removal was analyzed over the $\mathrm{pH}$ range from 2 to 5 and for different contact times. Figure 7 shows the effect of $\mathrm{pH}$ and agitation time on dye removal by $\mathrm{PC}$. As expected, the $\mathrm{pH}$ significantly affected the extent of adsorption of dye over both the adsorbents, and a reduction in the amount adsorbed with increasing $\mathrm{pH}$ was observed in both cases. This trend is in agreement with earlier report on anionic dye adsorption [6]. This behavior can be explained on the basis of change in surface charge of the lignocellulosic materials. By increasing the $\mathrm{pH}$, the surface of adsorbents get more negatively charged (Figure 3), which does not favor the adsorption of dye anions due to the electrostatic repulsion. The maximum biosorption capacity reached was at $\mathrm{pH}$ 2. The equilibrium time was found to be 8 and $4 \mathrm{~h}$ for PC and OC, respectively. Although surface negativity of both sorbents was similar, the uptake of dye by OC occurred faster than PC. This may show that the covalent coordination bonds between dye molecules and surface functional groups is also important in adsorption as well as electrostatic forces.

In the case of modified pine cone and modified oak cups pulp, maximum dye uptake was obtained at $\mathrm{pH} 2$, as in the case of native biosorbents. The contact times of 6 and $4 \mathrm{hrs}$ for PC-N and OC-N were found to be sufficient to attain equilibrium. As in the case of basic dye, the uptake of acidic dye by PC-N occurred faster than PC due to its less negative surface. In addition, it was noted that sorption of Acid Red 111 onto modified PC was more influenced by $\mathrm{pH}$ than that onto PC. The dye uptake drastically decreased above $\mathrm{pH} 3$ (Figure 8). 


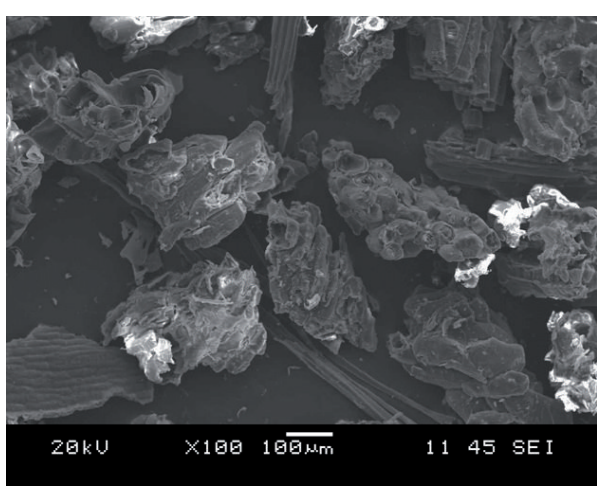

(a)

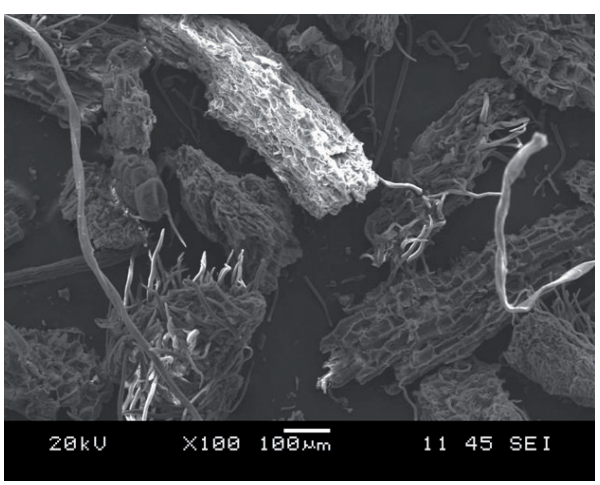

(c)

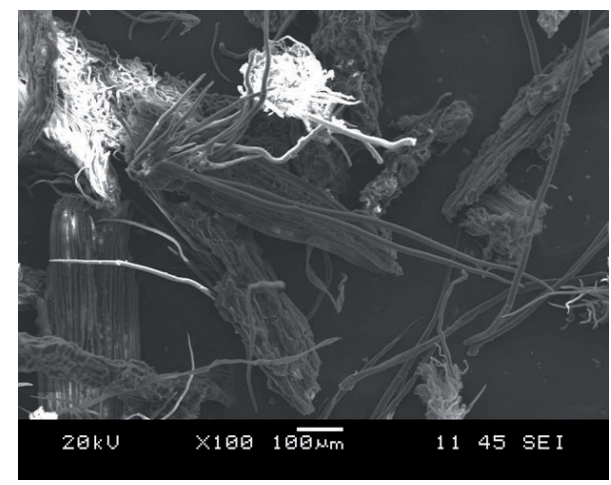

(b)

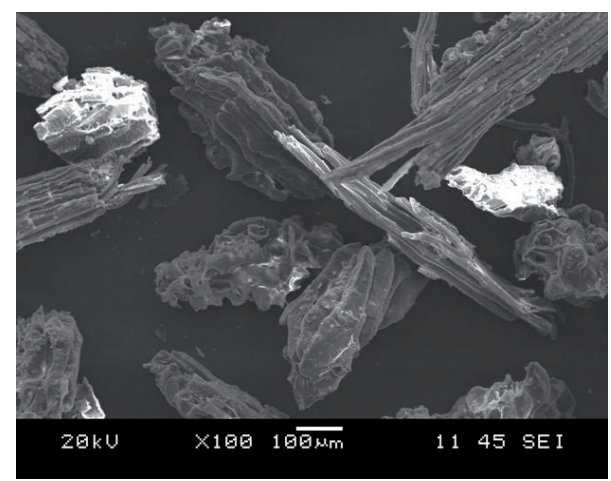

(d)

Figure 4: Micrograph of PC (a), PC-N (b), OC (c), and OC-N (d) (magnification: X100).

TABLE 4: Reported basic dye adsorption capacities for agricultural wastes.

\begin{tabular}{|c|c|c|c|}
\hline Adsorbent & Adsorbate & $S_{M}\left(\mathrm{mgg}^{-1}\right)$ & Reference \\
\hline Beach sawdust & Methylene blue & 10.9 & [3] \\
\hline Wood shavings & Methylene blue & 17.9 & {$[22]$} \\
\hline Tea wates & Methylene blue & 156.0 & {$[8]$} \\
\hline Beech sawdust & Methylene blue & 9.8 & {$[4]$} \\
\hline Palm kernel fibre & Methylene blue & 671.8 & {$[11]$} \\
\hline Rice straw & Malachite green & 94.3 & {$[23]$} \\
\hline Modified rice straw & Malachite green & 256.41 & {$[23]$} \\
\hline Hen feather & Malachite green & 9.4 & {$[36]$} \\
\hline Luffa cylindrica & Malachite green & 29.4 & {$[28]$} \\
\hline Sunflower seed hull & Methyl violet & 92.6 & {$[10]$} \\
\hline Banana peel & Methyl violet & 12.2 & {$[5]$} \\
\hline Orange peel & Methyl violet & 11.5 & {$[5]$} \\
\hline Coir pith & Rhodamine B & 203.2 & {$[12]$} \\
\hline Canola hul & Basic Blue 41 & 67.6 & {$[18]$} \\
\hline Canola hull & Basic Red 46 & 49.0 & {$[18]$} \\
\hline Canola hull & Basic Violet 16 & 25.0 & {$[18]$} \\
\hline
\end{tabular}

3.4. Cr (VI) Adsorption. Several lignocellulosic wastes have been investigated for chromium removal. Mohan and Pittman. have reviewed the sorption capacities of lignocellulosic sorbents for chromium remediation [31]. In the adsorption of Cr (VI) on lignocellulosic material, two mechanism, namely, adsorption and reduction to trivalent chromium, can simultaneously occur [14]. Some researchers have claimed that $\mathrm{Cr}(\mathrm{VI})$ was removed from the aqueous phase by binding of anionic $\mathrm{Cr}$ (VI) ion species to the positively charged groups of biosorbent [32]. But several authors reported that organic substances, such as lignocellulosic materials, have the capacity to reduce $\mathrm{Cr}$ (VI) to $\mathrm{Cr}$ (III) at acidic pHs 


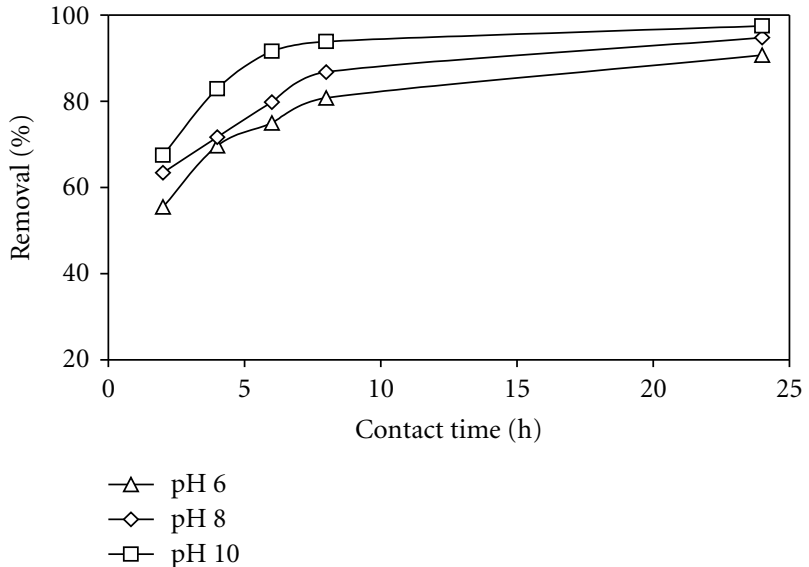

FIGURE 5: Effect of $\mathrm{pH}$ and contact time on basic dye removal by PC (adsorbent dosage, $500 \mathrm{mg}$ per $100 \mathrm{~mL}$; dye concentrations, $50 \mathrm{mg}$ $\left.\mathrm{L}^{-1}\right)$.

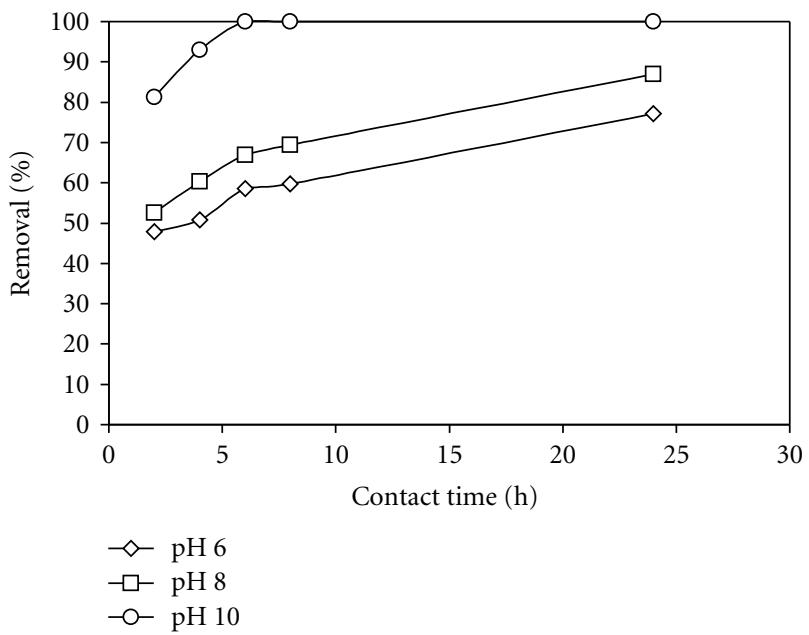

FIGURE 6: Basic dye adsorption capacity of PC-N as a function of contact time (adsorbent dosage, $500 \mathrm{mg}$ per $100 \mathrm{~mL}$; dye concentrations, $50 \mathrm{mg} \mathrm{L}^{-1}$ ).

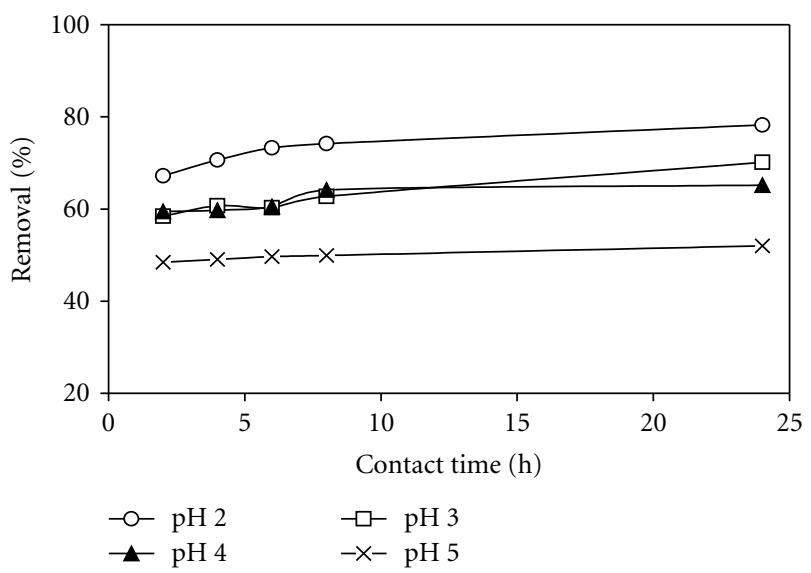

Figure 7: Acidic dye adsorption capacity of PC as a function of $\mathrm{pH}$ and contact time (adsorbent dosage, $500 \mathrm{mg}$ per $100 \mathrm{~mL}$; dye concentrations, $50 \mathrm{mg} \mathrm{L}^{-1}$ ).

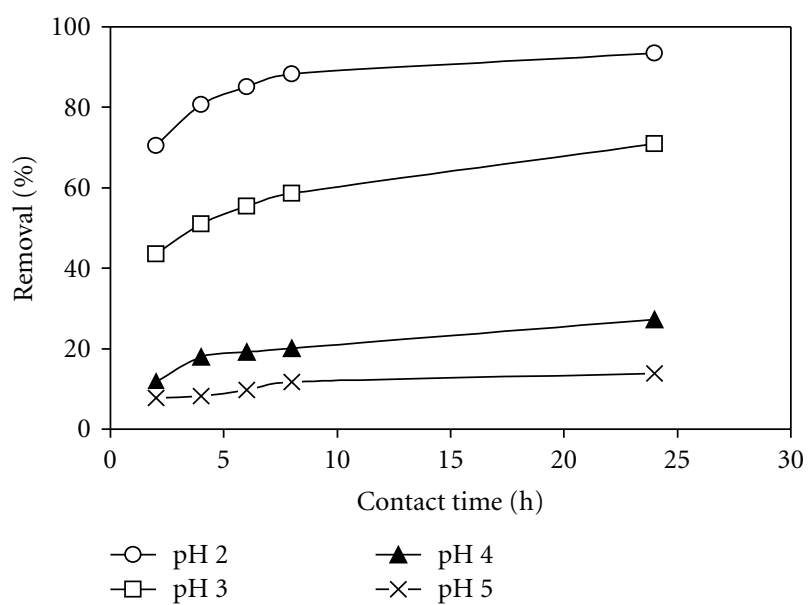

FIgURE 8: Acidic dye adsorption capacity of PC-N as a function of $\mathrm{pH}$ (adsorbent dosage, $500 \mathrm{mg}$ per $100 \mathrm{~mL}$ dye concentrations, $\left.50 \mathrm{mg} \mathrm{L}^{-1}\right)$.

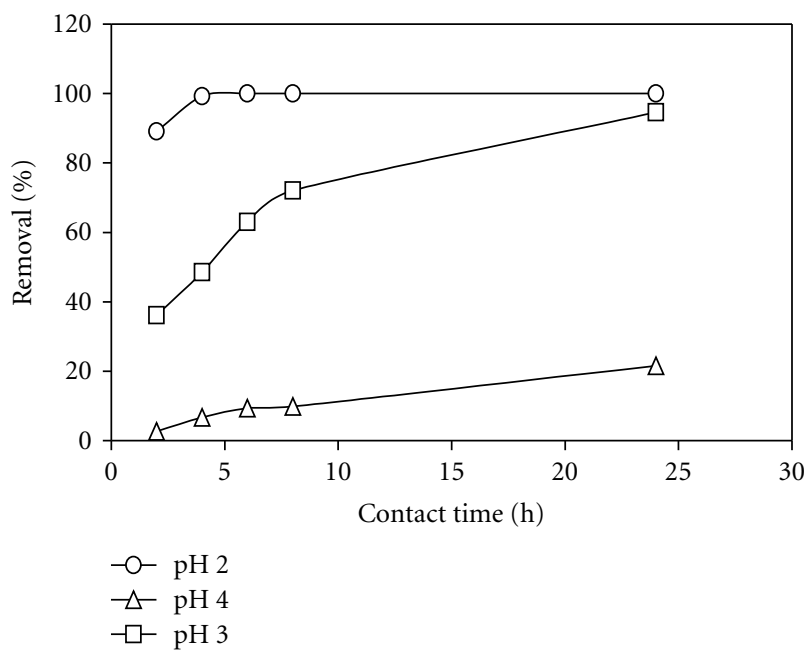

(a)

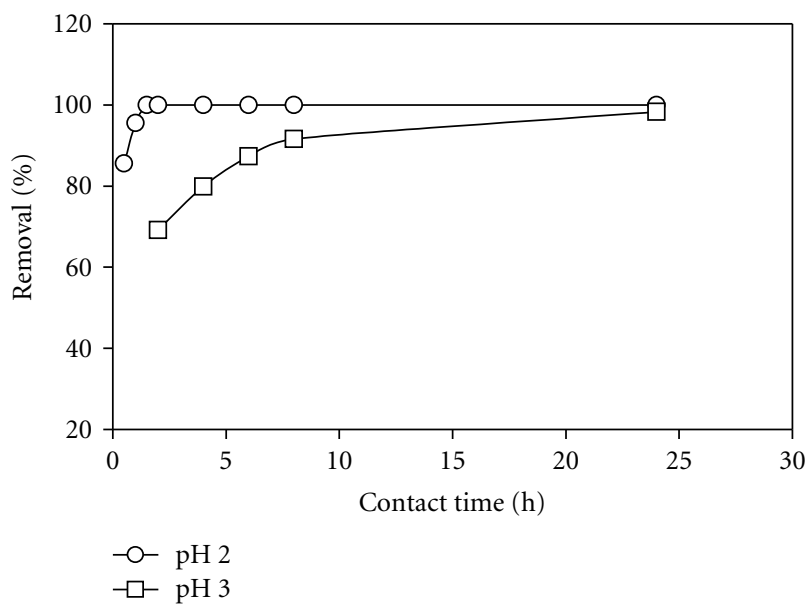

(b)

FIgURE 9: Cr (VI) adsorption capacity of PC (a) and OC (b) as a function of $\mathrm{pH}$ (Adsorbent dosage, $2500 \mathrm{mg}$ per $100 \mathrm{~mL}$; Cr (VI) concentration, $\left.10 \mathrm{mg} \mathrm{L}^{-1}\right)$. 
$[14,15,33]$. Fiol et al. [14] proposed that $\mathrm{Cr}$ (VI) sorption process involves two different mechanisms: adsorption of the $\mathrm{HCrO}_{4}{ }^{-}$anion and reduction of $\mathrm{Cr}$ (VI) to $\mathrm{Cr}$ (III) releasing into the solution totally or partially the formed trivalent chromium. They observed the adsorption of both trivalent and hexavalent chromium on grape stalks by XPS analysis in their study on $\mathrm{Cr}$ (VI) sorption.

As well known, the $\mathrm{pH}$ value of the solution is an important controlling parameter in the Cr (VI) adsorption process. The uptake of $\mathrm{Cr}$ (VI) increased with a decrease in the solution $\mathrm{pH}$. The $\mathrm{pH}$ dependence of the metal uptake is mainly related to the functional groups on the adsorbent and also on the metal solution chemistry. From $\mathrm{pH} 1$ to $\mathrm{pH} 6$, most chromium species exist in solution in the form $\mathrm{HCrO}_{4}{ }^{-}$, while from $\mathrm{pH} 6$ to $\mathrm{pH} 10$, the $\mathrm{CrO}_{4}{ }^{2-}$ species become predominant in solution. As expected, the adsorption capacity of chromium onto both lignocellulosic materials decreases with increasing $\mathrm{pH}$ (Figure 9). Similar behavior has also been reported for yohimbe bark [14], soya cake [15], and lignocellulosic substrate derived from wheat bran [33]. This phenomenon can be attributed to the fact that a lower $\mathrm{pH}$ decreases the negatively charged groups on the surface of sorbents (Figure 3), which leads to higher $\mathrm{Cr}$ (VI) uptake. In addition, by considering the above explanations, one can also say that reduction of $\mathrm{Cr}$ (VI) to $\mathrm{Cr}$ (III) may also lead to a decrease in concentration of $\mathrm{Cr}(\mathrm{VI})$ in solution. It is seen that $\mathrm{pH} 2.0$ is the optimal $\mathrm{pH}$ for the $\mathrm{Cr}(\mathrm{VI})$ uptake for both adsorbents. But, the Cr (VI) uptake by OC occurred faster than that by PC. Almost $100 \%$ of adsorption was achieved for the contact times $1 \mathrm{~h}$ and $4 \mathrm{hrs}$ at $\mathrm{pH} 2$ for OC and PC, respectively. Although surface negativity of both sorbents was similar, there is a significant difference between optimum contact times of OC and PC. This shows that the complex formation and/or chelation between chromium ions and surface functional groups [17] is also important in adsorption as well as electrostatic forces at acidic condition. It must be remarked that for longer contact time ( $24 \mathrm{hrs})$, the removal efficiency of both $\mathrm{PC}$ and $\mathrm{OC}$ at $\mathrm{pH} 3$ was similar within the case of $\mathrm{pH} 2$.

For modified pine cone and modified oak cups pulp, maximum chromium uptake was obtained at $\mathrm{pH} 2$. The uptake of $\mathrm{Cr}$ (VI) by PC-N occurred faster than PC, corresponding to $93.3 \%$ removal at an equilibrium time of $3 \mathrm{~h}$. The reason might be the increase in available adsorption sites area by the modification of $\mathrm{PC}$ with $\mathrm{HNO}_{3}$ treatment. In the case of OC$\mathrm{N}$, almost $100 \%$ of adsorption was obtained for the contact time $1 \mathrm{~h}$ at $\mathrm{pH} 2$, as in the case of OC.

3.5. Biosorption Equilibrium. The adsorption isotherm indicates how the adsorbate molecules distribute between the liquid phase and the adsorbent when the biosorption process reaches an equilibrium state. For practical operation, correlation of the isotherms using a theoretical or empirical equation is desired. In this study, two common isotherms were used for describing the experimental results, namely, the Freundlich isotherm and the Langmuir isotherm. The parameters in Freundlich and Langmuir equations are very useful for predicting adsorption capacities and also for incorporating into mass transfer relationships in the design of contacting equipment.

The Freundlich model is considered to be suitable for highly heterogeneous surfaces and indicates that significant adsorption takes place at low concentrations, but the increase in the amount adsorbed with concentration becomes less significant at higher concentration. Although the used adsorbents were natural adsorbent exhibiting the chemical heterogeneity [34], the experimental results for all tested adsorbates fitted best to Langmuir model.

The Langmuir equation describes adsorption on strongly homogeneous surfaces, which is not the case of natural adsorbents exhibiting first of all a chemical heterogeneity represented by the different functional groups. Langmuir model is based on the assumption of monolayer adsorption onto a surface containing finite number of adsorption sites of uniform energies of adsorption with no transmigration of adsorbate in the pores of the adsorbent surface [35]. The linear form of Langmuir isotherm is given by the following equation:

$$
\frac{C e}{q e}=\frac{1}{K_{L} S_{M}}+\frac{C e}{S_{M}},
$$

where, $S_{M}\left(\mathrm{mg} \mathrm{g}^{-1}\right)$ is the maximum amount of adsorption corresponding to complete monolayer coverage on the surface, $q e\left(\mathrm{mg} \mathrm{g}^{-1}\right)$ is the amount of dye, $K_{L}\left(\mathrm{lg}^{-1}\right)$ is the Langmuir constant, and $\mathrm{Ce}$ is the equilibrium liquid phase concentrations of dye solution.

The isotherm parameters obtained for dyes and $\mathrm{Cr}$ (VI) are reported in Table 3. Both PC-N and OC adsorbed the Basic Red 18 in a greater degree in comparison with the other adsorbents within this study. Although, the FT-IR spectrum of adsorbents did not differ significantly from each other, suggesting that the treatment process did not change the lignocellulose structure substantially; however, the adsorption capacities of modified sorbents for basic dye are different from that of natural sorbents. For example, modification of oak cups pulp led to decrease its basic dye adsorption capacity. The reason may be higher negative surface charge of OC than that of OC-N, which favors adsorption between the positively charged dye ion and the surface of OC by electrostatic interaction. On the other hand, the adsorption capacity of PC-N is higher than that of PC; even C-N has lesser surface negativity than PC. It may be due to the fact that $\mathrm{HNO}_{3}$ treatment affected the accessibility of some functional groups on the surface of adsorbent, which may lead to changes in its adsorption behavior. The basic dye adsorption capacity of the adsorbents tested in this study can be compared with the other agricultural solid wastes (Table $4)$.

On the other hand, all the tested adsorbents showed low adsorption capacity for Acid Red 111 because the negative surface charge on the adsorbent does not favor the adsorption of dye anions due to the electrostatic repulsion. The similar aspect took place for other adsorbents in the literature. The adsorption capacities of all adsorbents for Acid Red 111 were ranged in $7.54-9.95 \mathrm{mg} \mathrm{g}^{-1}$ adsorbent. These values are quite comparable with the sorption capacities of natural 
materials as listed in the review of Crini [36]. The $S_{M}$ values reported in this paper are in the ranges $5.92-20 \mathrm{mg} / \mathrm{g}$ for acidic dyes. However, the adsorption capacities of soy meal hull for C.I.Direct red 80, C.I.Direct red 81, C.I.Acid blue 92, and C.I.Acid red 14 were found to be 178.57, 120.48, 114.94, and $109.89 \mathrm{mg} \mathrm{g}^{-1}$ of adsorbent, respectively [16].

In addition, Mahmoodi et al. obtained the maximum adsorption capacities for Acid Black 26, Acid Green 25 and Acid Blue 7 onto Pine Cone (PC) as 62.89, 43.29 and $37.45 \mathrm{~g}^{-1}$, respectively [37]. The differences in adsorption capacities found in the literature might be not only attributed to surface characteristics of adsorbent, it might be also attributed to the size and shape of the dye molecule.

It was evident from the present study that both pine cone and oak cups pulp showed similar $\mathrm{Cr}$ (VI) adsorption capacity, and modification of native sorbents could not enhance their adsorption capacities. The adsorption capacities for $\mathrm{Cr}$ (VI) were ranged in $4.19-8.36 \mathrm{mg} \mathrm{g}^{-1}$ adsorbent. It must be noted that the used adsorbents in this study had lower $\mathrm{Cr}$ (VI) adsorption capacities than some of the lignocellulosic based adsorbents found in the literature. Mohan and Pittman reviewed the remediation of tri- and hexavalent chromium from water by activated carbons and low-cost adsorbents [31]. The $S_{M}$ values reported in this review are in the range of $0.2-103 \mathrm{mg} \mathrm{g}^{-1}$ for lignocelluloses based adsorbents.

\section{Conclusions}

This study demonstrated that the raw and acid-treated oak cups pulp and pine cone could be used as efficient biosorbent for the treatment of basic dyes containing aqueous solutions. The chemical modification of pine cone with nitric acid enhanced the basic dye adsorption capacity due to the increase number of available adsorption sites. In contrast, chemical modification of oak cups pulp decreased its dye adsorption capacity due to the less negative surface charge of modified biosorbent. It has been concluded that the use of oak cups pulp is more economic than pine cone because it does not require an additionl pretreatment step, and the adsorption can be done at a wide range $\mathrm{pH}$ between 6 and 10. On the other hand, both two biosorbents were not much effective for acidic dye and chromium removal. Modification of biosorbents could not enhance their acidic dye and $\mathrm{Cr}(\mathrm{VI})$ uptake capacities.

\section{Acknowledgments}

The authors would like thank to Ege University for financial support under the Contract 2009-ÇSUM-002.

\section{References}

[1] M. M. Nassar and M. S. El-Geundi, "Comparative cost of colour removal from textile effluents using natural adsorbents," Journal of Chemical Technology and Biotechnology, vol. 50, no. 2, pp. 257-264, 1991.

[2] R. Y. L. Yeh and A. Thomas, "Color difference measurement and color removal from dye wastewaters using different adsorbents,"
Journal of Chemical Technology and Biotechnology, vol. 63, no. 1, pp. 55-59, 1995.

[3] F. A. Batzias and D. K. Sidiras, "Simulation of dye adsorption by beech sawdust as affected by $\mathrm{pH}$," Journal of Hazardous Materials, vol. 141, no. 3, pp. 668-679, 2007.

[4] F. A. Batzias and D. K. Sidiras, "Dye adsorption by prehydrolysed beech sawdust in batch and fixed-bed systems," Bioresource Technology, vol. 98, no. 6, pp. 1208-1217, 2007.

[5] G. Annadurai, R. S. Juang, and D. J. Lee, "Use of cellulose-based wastes for adsorption of dyes from aqueous solutions," Journal of Hazardous Materials, vol. 92, no. 3, pp. 263-274, 2002.

[6] M. Arami, N. Y. Limaee, N. M. Mahmoodi, and N. S. Tabrizi, "Removal of dyes from colored textile wastewater by orange peel adsorbent: equilibrium and kinetic studies," Journal of Colloid and Interface Science, vol. 288, no. 2, pp. 371-376, 2005.

[7] B. C. Qi and C. Aldrich, "Biosorption of heavy metals from aqueous solutions with tobacco dust," Bioresource Technology, vol. 99, no. 13, pp. 5595-5601, 2008.

[8] N. Nasuha, B. H. Hameed, and A. T. M. Din, "Rejected tea as a potential low-cost adsorbent for the removal of methylene blue," Journal of Hazardous Materials, vol. 175, no. 1-3, pp. 126-132, 2010.

[9] A. Mittal, "Adsorption kinetics of removal of a toxic dye, malachite green, from wastewater by using hen feathers," Journal of Hazardous Materials, vol. 133, no. 1-3, pp. 196-202, 2006.

[10] B. H. Hameed, "Equilibrium and kinetic studies of methyl violet sorption by agricultural waste," Journal of Hazardous Materials, vol. 154, no. 1-3, pp. 204-212, 2008.

[11] A. E. Ofomaja, "Kinetics and mechanism of methylene blue sorption onto palm kernel fibre," Process Biochemistry, vol. 42, no. 1, pp. 16-24, 2007.

[12] C. Namasivayam, M. Dinesh Kumar, K. Selvi, R. Ashruffunissa Begum, T. Vanathi, and R. T. Yamuna, "Waste' coir pith-a potential biomass for the treatment of dyeing wastewaters," Biomass and Bioenergy, vol. 21, no. 6, pp. 477-483, 2001.

[13] R. Gong, Y. Ding, C. Yang, M. Li, H. Liu, and Y. Sun, "Utilization of powdered peanut hull as biosorbent for removal of anionic dyes from aqueous solution," Dyes and Pigments, vol. 64, no. 3, pp. 187-192, 2005.

[14] N. Fiol, C. Escudero, and I. Villaescusa, "Chromium sorption and $\mathrm{Cr}(\mathrm{VI})$ reduction to $\mathrm{Cr}(\mathrm{III})$ by grape stalks and yohimbe bark," Bioresource Technology, vol. 99, no. 11, pp. 5030-5036, 2008.

[15] N. Daneshvar, D. Salari, and S. Aber, "Chromium adsorption and $\mathrm{Cr}(\mathrm{VI})$ reduction to trivalent chromium in aqueous solutions by soya cake," Journal of Hazardous Materials, vol. 94, no. 1, pp. 49-61, 2002.

[16] M. Arami, N. Y. Limaee, N. M. Mahmoodi, and N. S. Tabrizi, "Equilibrium and kinetics studies for the adsorption of direct and acid dyes from aqueous solution by soy meal hull," Journal of Hazardous Materials, vol. 135, no. 1-3, pp. 171-179, 2006.

[17] Z. Aksu and I. A. Isoglu, "Use of dried sugar beet pulp for binary biosorption of Gemazol Turquoise Blue-G reactive dye and copper(II) ions: equilibrium modeling," Chemical Engineering Journal, vol. 127, no. 1-3, pp. 177-188, 2007.

[18] N. M. Mahmoodi, M. Arami, H. Bahrami, and S. Khorramfar, "Novel biosorbent (Canola hull): surface characterization and dye removal ability at different cationic dye concentrations," Desalination, vol. 264, no. 1-2, pp. 134-142, 2010.

[19] V. K. Gupta and A. Rastogi, "Biosorption of hexavalent chromium by raw and acid-treated green alga Oedogonium 
hatei from aqueous solutions," Journal of Hazardous Materials, vol. 163, no. 1, pp. 396-402, 2009.

[20] M. C. Ncibi, B. Mahjoub, and M. Seffen, "Adsorptive removal of textile reactive dye using Posidonia oceanica (L.) fibrous biomass," International Journal of Environmental Science and Technology, vol. 4, no. 4, pp. 433-440, 2007.

[21] D. Inthorn, S. Singhtho, P. Thiravetyan, and E. Khan, "Decolorization of basic, direct and reactive dyes by pre-treated narrow-leaved cattail (Typha angustifolia Linn.)," Bioresource Technology, vol. 94, no. 3, pp. 299-306, 2004.

[22] P. Janoš, S. Coskun, V. Pilařová, and J. Rejnek, "Removal of basic (Methylene Blue) and acid (Egacid Orange) dyes from waters by sorption on chemically treated wood shavings," Bioresource Technology, vol. 100, no. 3, pp. 1450-1453, 2009.

[23] R. Gong, Y. Jin, F. Chen, J. Chen, and Z. Liu, "Enhanced malachite green removal from aqueous solution by citric acid modified rice straw," Journal of Hazardous Materials, vol. 137, no. 2, pp. 865-870, 2006.

[24] E. E. Saka and C. Güler, "The effects of electrolyte concentration, ion species and $\mathrm{pH}$ on the zeta potential and electrokinetic charge density of montmorillonite," Clay Minerals, vol. 41, no. 4, pp. 853-861, 2006.

[25] F. Suárez-García, A. Martínez-Alonso, and J. M. D. Tascón, "A comparative study of the thermal decomposition of apple pulp in the absence and presence of phosphoric acid," Polymer Degradation and Stability, vol. 75, no. 2, pp. 375-383, 2002.

[26] K. Stana-Kleinschek and V. Ribitsch, "Electrokinetic properties of processed cellulose fibers," Colloids and Surfaces A, vol. 140, no. 1-3, pp. 127-138, 1998.

[27] C. Bellmann, A. Caspari, V. Albrecht et al., "Electrokinetic properties of natural fibres," Colloids and Surfaces A, vol. 267, no. 1-3, pp. 19-23, 2005.

[28] A. Altınısık, E. Gür, and Y. Seki, "A natural sorbent, Luffa cylindrica for the removal of a model basic dye," Journal of Hazardous Materials, vol. 179, no. 1-3, pp. 658-664, 2010.

[29] R. Sanghi and B. Bhattacharya, "Review on decolorisation of aqueous dye solutions by low cost adsorbents," Coloration Technology, vol. 118, no. 5, pp. 256-269, 2002.

[30] Y. Fu and T. Viraraghavan, "Removal of Congo Red from an aqueous solution by fungus Aspergillus niger," Advances in Environmental Research, vol. 7, no. 1, pp. 239-247, 2002.

[31] D. Mohan and C. U. Pittman, "Activated carbons and low cost adsorbents for remediation of tri- and hexavalent chromium from water," Journal of Hazardous Materials, vol. 137, no. 2, pp. 762-811, 2006.

[32] E. Malkoç and Y. Nuhoglu, "The removal of chromium(VI) from synthetic wastewater by Ulothrix zonata," Fresenius Environmental Bulletin, vol. 12, no. 4, pp. 376-381, 2003.

[33] L. Dupont and E. Guillon, "Removal of hexavalent chromium with a lignocellulosic substrate extracted from wheat bran," Environmental Science and Technology, vol. 37, no. 18, pp. 4235-4241, 2003.

[34] M. M. Dávila-Jiménez, M. P. Elizalde-González, and A. A. Peláez-Cid, "Adsorption interaction between natural adsorbents and textile dyes in aqueous solution," Colloids and Surfaces A, vol. 254, no. 1-3, pp. 107-114, 2005.

[35] G. Duman, Y. Onal, C. Okutucu, S. Onenc, and J. Yanik, "Production of activated carbon from pine cone and evaluation of its physical, chemical, and adsorption properties," Energy and Fuels, vol. 23, no. 4, pp. 2197-2204, 2009.
[36] G. Crini, "Non-conventional low-cost adsorbents for dye removal: a review," Bioresource Technology, vol. 97, no. 9, pp. 1061-1085, 2006.

[37] N. M. Mahmoodi, B. Hayati, M. Arami, and C. Lan, "Adsorption of textile dyes on Pine Cone from colored wastewater: kinetic, equilibrium and thermodynamic studies," Desalination, vol. 268, no. 1-3, pp. 117-125, 2011. 

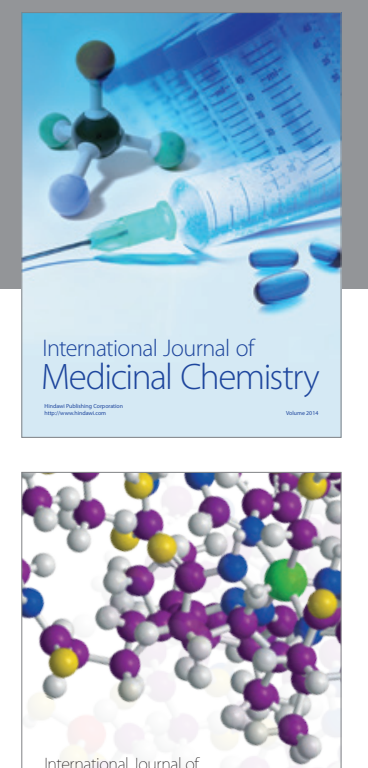

\section{Carbohydrate} Chemistry

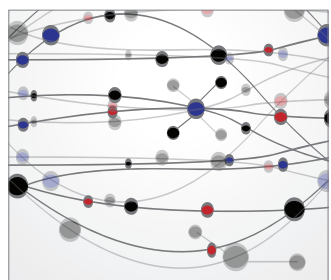

The Scientific World Journal
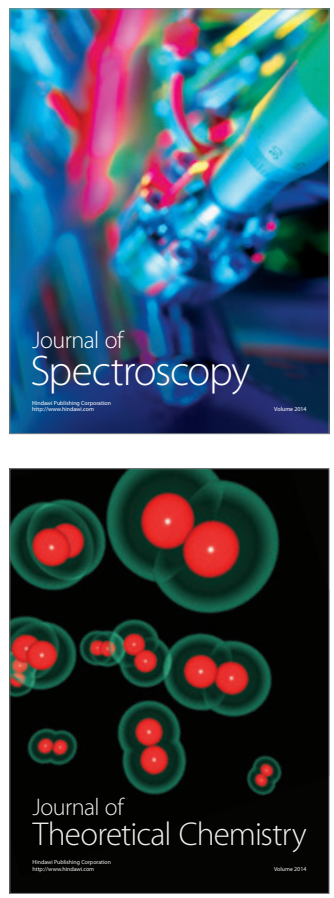
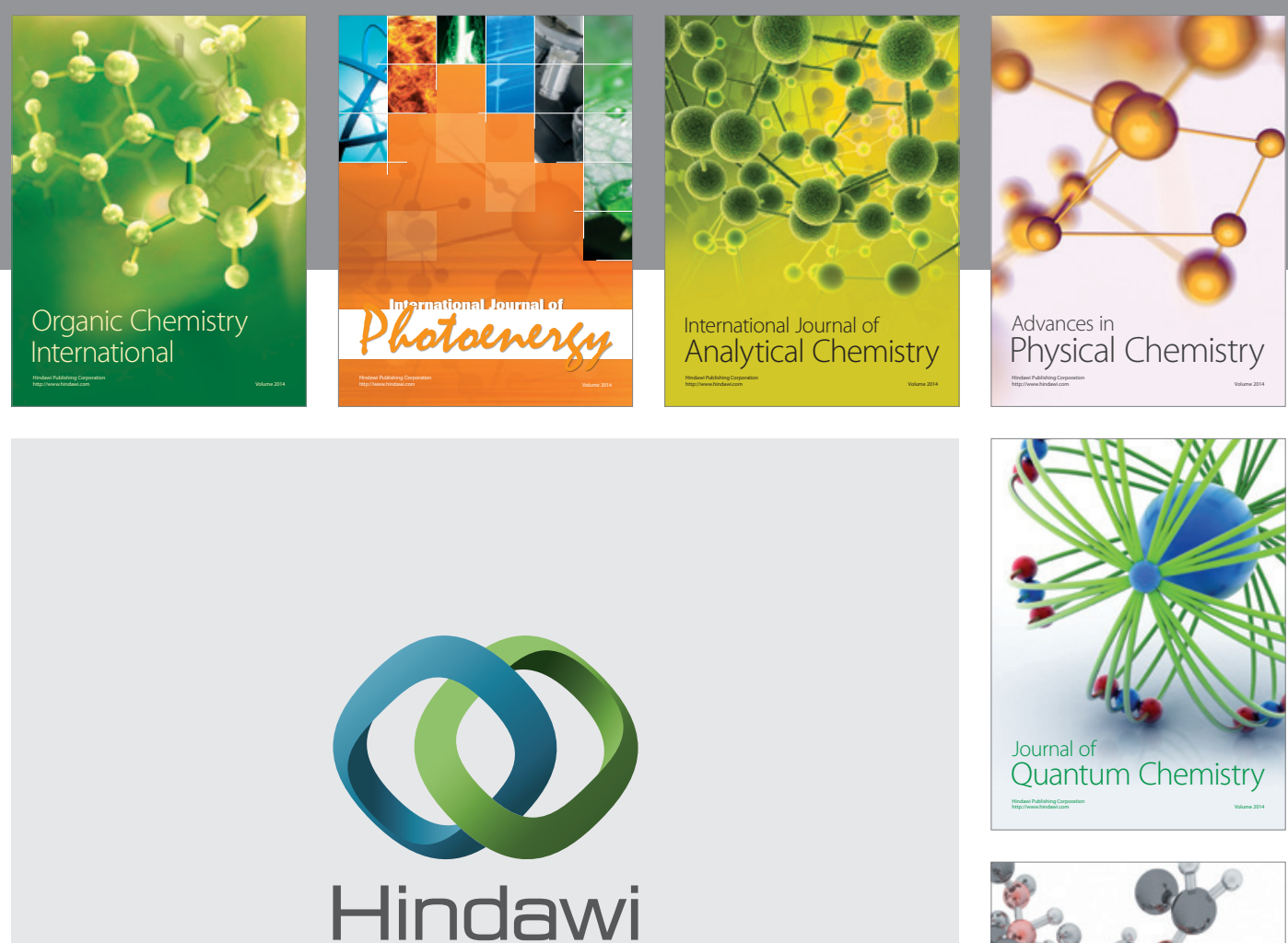

Submit your manuscripts at

http://www.hindawi.com

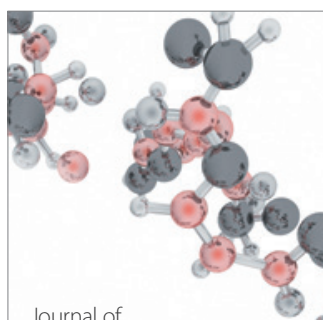

Analytical Methods

in Chemistry

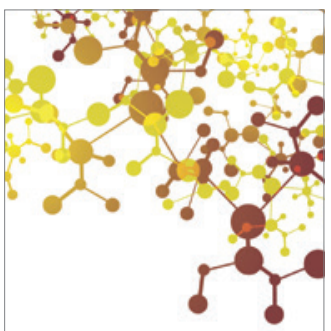

Journal of

Applied Chemistry

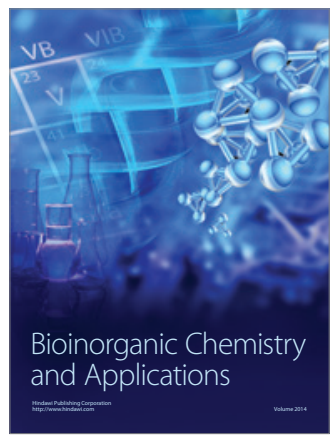

Inorganic Chemistry
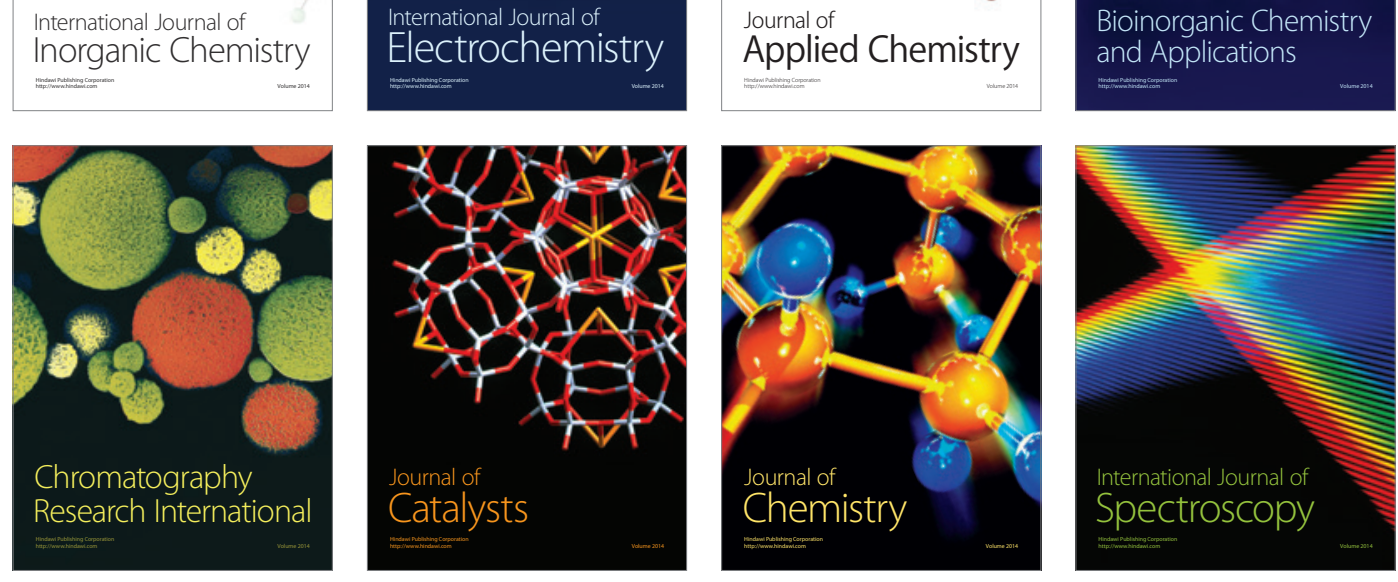